\title{
Robust Positioning Control Using $\alpha-\beta$ Stationary Frame Current Controller and Disturbance Torque Hybrid Observer
}

\author{
Yoshiaki Seki* Student Member, Kiyoshi Ohishi* Fellow \\ Yuki Yokokura* Member, Toshiki Sano* Student Member \\ Yuji Ide* \\ Daigo Kuraishi** Member \\ Member, \\ Akihiko Takahashi** Non-member
}

(Manuscript received March 5, 2016, revised Sep. 7, 2016)

\begin{abstract}
In the field of high precision positioning control, the position servo system must be highly robust against disturbance torque. A Permanent Magnet Synchronous Motor (PMSM) has various torque ripple components that degrade control performance. A portion of the torque ripple is caused by the harmonic current. The torque ripple can be suppressed using a highly robust current control system. The remaining torque ripple is defined as the disturbance torque and is compensated for using a Disturbance OBserver (DOB). However, it is very difficult for a DOB to perform the appropriate compensation because it uses a low-pass filter to reduce noise. To obtain highly robust performance, this paper proposes a new position servo system using a disturbance torque hybrid observer and a current control system in the $\alpha-\beta$ stationary frame. In addition, this paper uses the torque ripple equation instead of a torque ripple table so as to reduce the amount of Digital Signal Processor (DSP) memory. The effectiveness of the proposed position servo system is confirmed using numerical and experimental results.
\end{abstract}

Keywords: PMSM, positioning control, robust control, disturbance observer, torque ripple suppression

\section{Introduction}

Position servo system, which is used in industrial applications, requires robust control. Robust control means that the system has a high robust performance against all disturbances $^{(1)(2)}$. In the field of high precision positioning control, disturbance torque decreases its control performance, e.g., the positioning accuracy decreases. Moreover, constraints on the motor structure occur.

When a Permanent Magnet Synchronous Motor (PMSM) is controlled, various components of a torque ripple are generated. Cogging torque occurs because of the motor structure between the stator and rotor-mounted permanent magnets. The flux harmonics of a PMSM cause torque ripple ${ }^{(3)-(5)}$. In addition, the dead time of the three-phase inverter, and the offset and scaling errors of the current sensor in experimental systems cause torque ripples ${ }^{(6)-(8)}$. They act as disturbance torque for a PMSM.

The current control system is required to have highly robust performance so as to reduce the harmonic current. In general, PI current control in the d-q synchronous frame is used as the current control system. The current control system has different disturbance suppression characteristics in the positive phase and negative phase. To obtain the same characteristics in both phases, a current control system in the $\alpha-\beta$ stationary frame is used.

\footnotetext{
${ }^{*}$ Motion Control Labs., Nagaoka University of Technology

1603-1, Kamitomioka, Nagaoka, Niigata 940-2188, Japan

** SANYO DENKI CO., LTD.

812-3, Shimonogo, Ueda, Nagano 386-1211, Japan
}

Recently, a Disturbance OBserver (DOB), which is very useful, has been widely used in the field of industrial applications $^{(9)-(16)}$. In particular, a DOB is used to compensate for disturbance torque. However, a DOB uses a low-pass filter for noise reduction, and it causes phase and amplitude shifts of an estimated value. This low-pass filter affects the estimated torque ripple components. As a result, it is very difficult to accurately estimate the instantaneous disturbance torque and compensate for it effectively.

To suppress torque ripple to achieve robust positioning control, several methods have been proposed. These methods, which use iterative learning control ${ }^{(17)}$, a repetitive current control ${ }^{(18)}$ method, are very effective for suppressing torque ripple in the steady state. It is difficult to design a controller for these approaches, which complicates the stability analysis. Moreover, these approaches sometimes cannot compensate for instantaneous disturbance torque.

To compensate for the instantaneous disturbance torque, several methods have been proposed. In the method in which multiple tables are utilized ${ }^{(19)}$, it is possible to instantaneously compensate for the disturbance torque (as it is saved in the table). However, it is impossible to compensate for the disturbance torque (as it is not saved the table). When a method utilizes the sixth-harmonic back electromotive force, which is estimated using the observer ${ }^{(20)}$, it is possible to instantaneously compensate for the sixth-harmonic disturbance torque. However, the method is susceptible to parameter variation. In the method that uses the table and the periodic disturbance observer ${ }^{(21)}$, it is possible to quickly and accurately compensate for the periodic disturbance torque. However, 

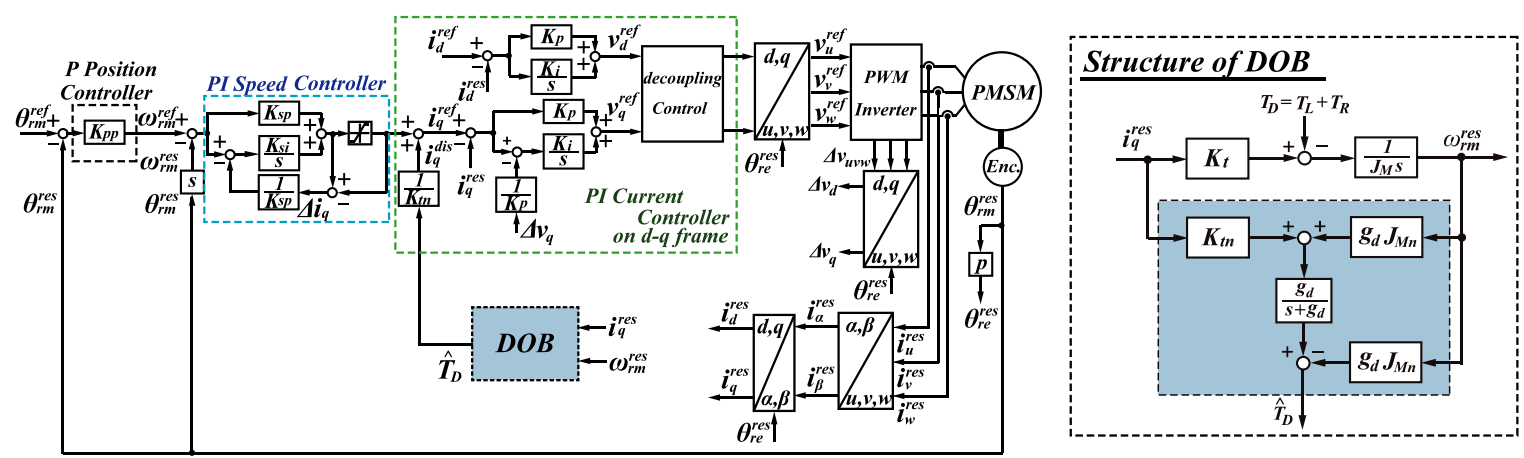

Fig. 1. Structure of DOB and block diagram of conventional position servo system applied to DOB

the calculation amount of the method is large.

To obtain highly robust performance, this paper proposes a new position servo system using the disturbance torque hybrid observer and the current control system in the $\alpha-\beta$ stationary frame. When the instantaneous disturbance torque is accurately estimated, the disturbance torque hybrid observer provides highly robust performance. The disturbance torque hybrid observer includes the DOB and the torque ripple table, and accurately and quickly compensates for the harmonic disturbance torque. Moreover, this paper considers the application of a torque ripple equation instead of a torque ripple table to save the amount of Digital Signal Processor (DSP) memory.

In this paper, the numerical results confirm the validity of the disturbance torque hybrid observer. The effectiveness of the proposed position servo system is well confirmed by the experimental results.

\section{Dynamics Model of PMSM}

When a PMSM has no flux saturations, no eddy currents, and no hysteresis losses, the PMSM voltage equations are expressed as (1) on a $d-q$ synchronous frame ${ }^{(22)-(24)}$.

$$
\left[\begin{array}{l}
v_{d} \\
v_{q}
\end{array}\right]=\left[\begin{array}{cc}
R_{a}+s L_{d} & -\omega_{r e} L_{d} \\
\omega_{r e} L_{q} & R_{a}+s L_{q}
\end{array}\right]\left[\begin{array}{c}
i_{d} \\
i_{q}
\end{array}\right]+\left[\begin{array}{c}
0 \\
\omega_{r e} \Phi_{a}
\end{array}\right] \cdots \cdots
$$

Where, $i_{d}$ : $d$-axis current, $i_{q}: q$-axis current, $v_{d}: d$-axis voltage, $v_{q}: q$-axis voltage, $\Phi_{a}:$ linkage flux of permanent magnet, $R_{a}$ : winding resistance, $L_{d}$ : winding $d$-axis inductance, $L_{q}$ : winding $q$-axis inductance, $\omega_{r e}$ : electrical angular speed and $s=d / d t$.

If (1) is a surface permanent magnet synchronous motor (SPMSM), then $L_{d}=L_{q}=L_{a}$, and the output torque $T_{M}$ of the motor is determined by (2). The motor dynamics equation is expressed as (3).

$$
\begin{aligned}
& T_{M}=P_{n} \Phi_{a} i_{q}=K_{t} i_{q} \ldots \ldots \ldots \ldots \ldots \ldots \ldots \ldots \ldots \\
& J_{M} \omega_{r m} s=K_{t} i_{q}-\left(T_{R}+T_{L}\right) \\
& =K_{t} i_{q}-T_{D}
\end{aligned}
$$

Where, $P_{n}$ : number of pole pairs and $K_{t}$ : torque constant, $J_{M}$ : motor-shaft inertia, $\omega_{r m}$ : mechanical angular speed, $T_{R}$ : known torque ripple components, $T_{L}$ : other disturbance torque (non-periodic components) and $T_{D}$ : total disturbance torque. Here the $T_{L}$ is defined as (6).

$$
\begin{aligned}
& J_{M}=J_{M n}+\Delta J_{M} \\
& K_{t}=K_{t n}+\Delta K_{t} \cdots
\end{aligned}
$$

$$
T_{L}=T_{l}+D_{M} \omega_{r m}+\Delta J_{M} \omega_{r m} s-\Delta K_{t} i_{q} \cdots \cdots \cdots
$$

Where, $(\text { script })_{n}$ : nominal parameter, $\Delta J_{M}$ and $\Delta K_{t}$ : variations from the each nominal parameter, $T_{l}$ : load-side torque and $D_{M}$ : frictional coefficient.

\section{Conventional Position Servo System}

Figure 1 shows the structure of DOB, which is a very simple structure ${ }^{(13)-(15)}$. A DOB has high robustness because it estimates and compensates for all components of disturbance torque, including the parameter variations $\Delta J_{M}$ and $\Delta K_{t}{ }^{(16)}$. The estimated total disturbance torque $\hat{T}_{D}$ is expressed as shown in (7). Here, a low-pass filter is used for noise reduction. A DOB is used to compensate for $T_{D}$, and (8) is derived. (8) can be transformed into (9).

$$
\begin{aligned}
\hat{T}_{D} & =\frac{g_{d}}{s+g_{d}}\left(\hat{T}_{L}+\hat{T}_{R}\right) \ldots \ldots \ldots \ldots \ldots \ldots \ldots \ldots \ldots \ldots \ldots \ldots \ldots \ldots \ldots \\
\hat{T}_{D} & =\frac{g_{d}}{s+g_{d}}\left(K_{t n} i_{q}-J_{M n} \omega_{r m} s\right) \ldots \ldots \ldots \ldots \ldots \\
\hat{T}_{D} & =\frac{g_{d}}{s+g_{d}}\left(K_{t n} i_{q}+g_{d} J_{M n} \omega_{r m}\right)-g_{d} J_{M n} \omega_{r m} \ldots \ldots
\end{aligned}
$$

Where, (script) is an estimated value and $g_{d}$ is the cut-off frequency of low-pass filter. Therefore, the instantaneous disturbance torque compensation current $i_{q}^{d i s}$ is expressed in (10).

$$
i_{q}^{d i s}=\frac{1}{K_{t n}} \hat{T}_{D}
$$

Figure 1 shows a block diagram of conventional position servo system applied to DOB. In Fig. 1, a P position controller, a PI speed controller, a $q$-axis current PI controller with the antiwindup control method ${ }^{(25)-(27)}$ and a $d$-axis current PI controller are used. The antiwindup algorithm of the $q$-axis current PI controller operates the calculation of its integrator by using the limited value $\Delta v_{q}$ of the $q$-axis voltage $^{(28)-(30)}$.

In DOB, a low-pass filter is used for noise reduction, as described in (9). However, this causes phase and amplitude shifts of the estimated value. This phenomenon has a significant impact on the estimated torque ripple $T_{R}$. Furthermore, when the bandwidth of the low-pass filter $g_{d}$ is high, it is impossible to obtain sufficient noise reduction. Therefore, the bandwidth $g_{d}$ has an upper limit. As a result, it is difficult to accurately estimate the instantaneous disturbance torque and perform effective compensation to achive robust positioning control. 

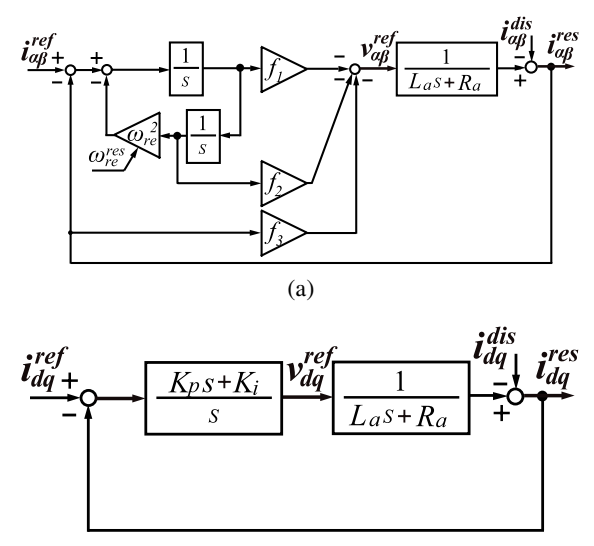

(b)

Fig. 2. Block diagram of both control systems. (a) Current control system on $\alpha-\beta$ stationary frame ( $\alpha-\beta$ sinusoidal current control). (b) Current control system on $d-q$ synchronous frame ( $d-q$ PI current control)

\section{Proposed Position Servo System}

4.1 Current Control System on $\alpha-\beta$ Stationary Frame In an $\alpha-\beta$ stationary frame, a harmonic current is composed the positive-phase components (for example, the 7th and 10th harmonics of the fundamental frequency $\omega_{r e}$ ) and negativephase components (for example, the 5th and 8th harmonics of the fundamental frequency $\omega_{r e}$ ). In order to reduce the harmonic current, it is necessary to obtain a high robust performance in both the positive-phase and negative-phase. In anddition, the robust performance in the positive and negative phases should be same to design easily the robust performance.

To obtain highly robust performance, this paper proposes a new current control system in the $\alpha-\beta$ stationary frame, called $\alpha-\beta$ sinusoidal current control. Figure 2(a) shows a block diagram of the $\alpha-\beta$ sinusoidal current control method.

In order to control the motor current on $\alpha-\beta$ stationary frame, it is necessary to design the current controller tracking to the direct and sinusoidal components. In Fig. 2(a), the current controller has the internal model with an integrator and sinusoidal dynamics. The transfer function to the current response $i_{\alpha \beta}^{\text {res }}$ from the current reference $i_{\alpha \beta}^{\text {ref }}$ is expressed as (11).

$$
G_{C(s)}^{\alpha \beta-\sin }=\frac{i_{\alpha \beta}^{r e s}}{i_{\alpha \beta}^{r e f}}=-\frac{b_{1} s+b_{0}}{a_{3} s^{3}+a_{2} s^{2}+a_{1} s+a_{0}}
$$

Where, $i_{\alpha \beta}^{r e f}=i_{\alpha}^{r e f}+j i_{\beta}^{r e f}, i_{\alpha \beta}^{r e s}=i_{\alpha}^{r e s}+j i_{\beta}^{r e s}, a_{3}=L_{a}, a_{2}=R_{a}+f_{3}$, $a_{1}=L_{a} \omega_{r e}^{2}-f_{1}, a_{0}=R_{a} \omega_{r e}^{2}+f_{3} \omega_{r e}^{2}-f_{2}, b_{1}=f_{1}, b_{0}=f_{2}$. Here, $f_{1}, f_{2}$, and $f_{3}$ are the current controller gains, which are variable gains that depend on the fundamental frequency $\omega_{r e}$. For example, $f_{1}, f_{2}$ and $f_{3}$, which are designed by the pole placement method as multiple roots in the desired pole $\omega_{c}$, are defined as (12), (13) and (14).

$$
\begin{aligned}
& f_{1}=L_{a}\left(\omega_{r e}^{2}-3 \omega_{c}^{2}\right) \ldots \\
& f_{2}=L_{a} \omega_{c}\left(3 \omega_{r e}^{2}-\omega_{c}^{2}\right) \\
& f_{3}=3 L_{a} \omega_{c}-R_{a} \ldots \ldots
\end{aligned}
$$

The transfer function to the current response $i_{\alpha \beta}^{\text {res }}$ from the disturbance $i_{\alpha \beta}^{d i s}$ is derived as (15).



Fig. 3. Equivalent $d-q$ PI current controller on $\alpha-\beta$ stationary frame

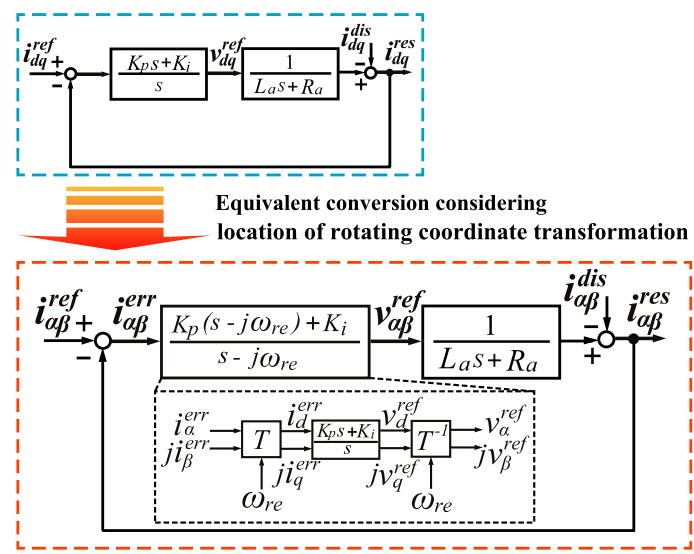

Fig. 4. Block diagram of equivalent $d-q$ PI current control system on $\alpha-\beta$ stationary frame

$$
G_{d i s(s)}^{\alpha \beta-\sin }=\frac{i_{\alpha \beta}^{r e s}}{i_{\alpha \beta}^{d i s}}=-\frac{c_{3} s^{3}+c_{2} s^{2}+c_{1} s+c_{0}}{a_{3} s^{3}+a_{2} s^{2}+a_{1} s+a_{0}}
$$

Where, $i_{\alpha \beta}^{d i s}=i_{\alpha}^{d i s}+j i_{\beta}^{d i s}, c_{3}=L_{a}, c_{2}=R_{a}, c_{1}=L_{a} \omega_{r e}^{2}$, $c_{0}=R_{a} \omega_{r e}^{2}$. Next, in order to confirm the effectiveness of the $\alpha-\beta$ sinusoidal current control, it is compared with the current control system on a $d-q$ synchronous frame, whose name is the $d-q$ PI current control as shown in Fig. 2(b). The input and output frames of the $d-q$ PI current control are different from them of the $\alpha-\beta$ sinusoidal current control. In order to analyze the performance of $d-q$ PI current control, this paper uses the rotating coordinate transformation $\mathrm{e}^{j \omega_{\text {ret }}}$ and $\mathrm{e}^{-j \omega_{\text {ret }}(\text { (31)(32) }}$. The $d-q$ PI current control is equivalently converted on the $\alpha-\beta$ stationary frame. Figure 3 shows the equivalent $d-q$ PI current controller on the $\alpha-\beta$ stationary frame. In Fig. 3 , the voltage reference on the $\alpha-\beta$ stationary frame $v_{\alpha \beta}^{\text {ref }}$ is defined in (20). Furthermore, (20) is rewritten as (21).

$$
\begin{aligned}
& v_{\alpha \beta}^{r e f}=v_{\alpha}^{r e f}+j v_{\beta}^{r e f} \\
& i_{\alpha \beta}^{e r r}=i_{\alpha \beta}^{r e f}-i_{\alpha \beta}^{r e s}=i_{\alpha}^{e r r}+j i_{\beta}^{e r r} \\
& T^{-1}=\left[\begin{array}{cc}
\cos \omega_{r e} t & j \sin \omega_{r e} t \\
j \sin \omega_{r e} t & \cos \omega_{r e} t
\end{array}\right]=\mathrm{e}^{j \omega_{r e} t} \\
& T=\left[\begin{array}{cc}
\cos \omega_{r e} t & -j \sin \omega_{r e} t \\
-j \sin \omega_{r e} t & \cos \omega_{r e} t
\end{array}\right]=\mathrm{e}^{-j \omega_{r e} t} \ldots \ldots \\
& {\left[\begin{array}{c}
v_{\alpha}^{r e f} \\
j v_{\beta}^{r e f}
\end{array}\right]=T^{-1}\left[\begin{array}{cc}
\frac{K_{p} s+K_{i}}{s} & 0 \\
0 & \frac{K_{p} s+K_{i}}{s}
\end{array}\right] T\left[\begin{array}{c}
i_{\alpha}^{e r r} \\
j i_{\beta}^{e r r}
\end{array}\right]} \\
& \frac{v_{\alpha \beta}^{r e f}}{i_{\alpha \beta}^{e r r}}=\frac{K_{p}\left(s-j \omega_{r e}\right)+K_{i}}{s-j \omega_{r e}}
\end{aligned}
$$

Where, $K_{p}$ and $K_{i}$ are the $d-q$ PI current controller gains. Figure 4 shows a block diagram of the equivalent $d-q$ PI current control system on the $\alpha-\beta$ stationary frame. As shown in 


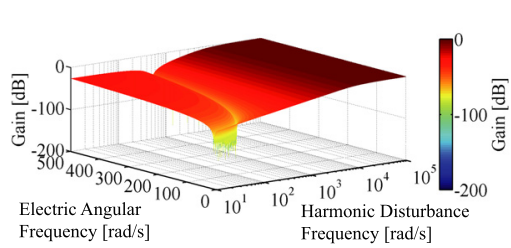

(a)

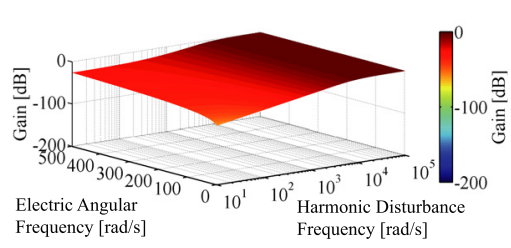

(c)

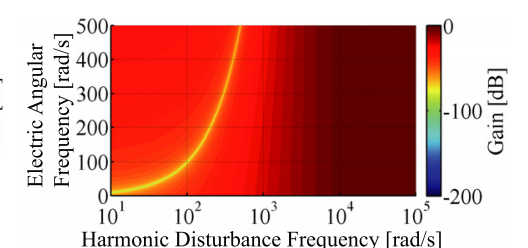

(b)



(d)

Fig. 5. Disturbance suppression performances of equivalent $d-q$ PI current control system on $\alpha-\beta$ stationary frame. (a) 3D bode diagram for suppression performance on POSITIVE-phase disturbance components. (b) Top view of (a). (c) 3D bode diagram for suppression performance on NEGATIVE-phase disturbance components. (d) Top view of (c)

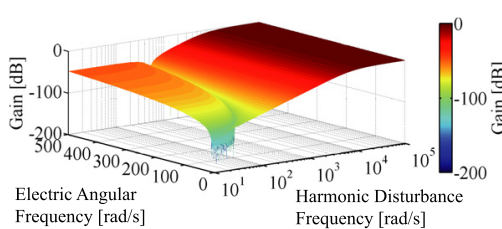

(a)

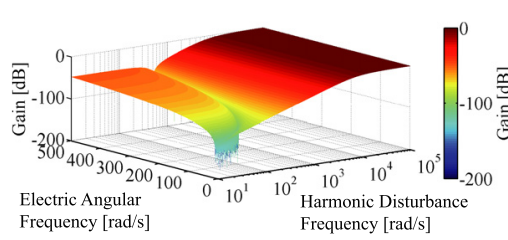

(c)

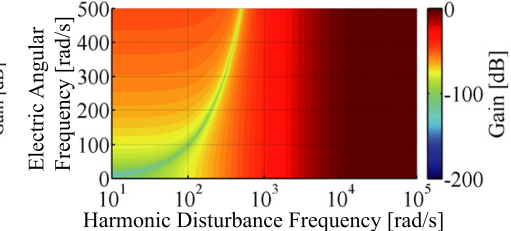

(b)

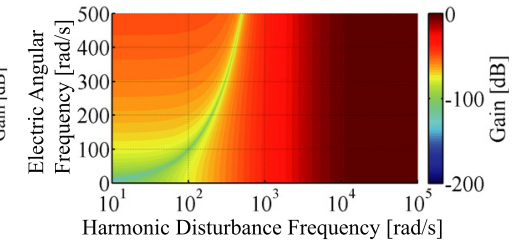

(d)

Fig. 6. Disturbance suppression performances of $\alpha-\beta$ sinusoidal current control system. (a) 3D bode diagram for suppression performance on POSITIVE-phase disturbance components. (b) Top view of (a). (c) 3D bode diagram for suppression performance on NEGATIVE-phase disturbance components. (d) Top view of (c)

Fig. 4, the transfer function of the current response $i_{\alpha \beta}^{\text {res }}$ obtained from the current reference $i_{\alpha \beta}^{\text {ref }}$ is derived as (22).

$$
G_{C(s)}^{d q-P I}=\frac{i_{\alpha \beta}^{r e s}}{i_{\alpha \beta}^{r e f}}=\frac{b_{1}^{\prime} s+b_{0}^{\prime}}{a_{2}^{\prime} s^{2}+a_{1}^{\prime} s+a_{0}^{\prime}} \ldots \ldots \ldots \ldots \ldots
$$

Where, $a_{2}^{\prime}=L_{a}, a_{1}^{\prime}=R_{a}+K_{p}-L_{a} j \omega_{r e}, a_{0}^{\prime}=K_{i}-\left(R_{a}+\right.$ $\left.K_{p}\right) j \omega_{r e}, b_{1}^{\prime}=K_{p}, b_{0}^{\prime}=K_{i}-K_{p} j \omega_{r e}$. The transfer function to the current response $i_{\alpha \beta}^{r e s}$ from the disturbance $i_{\alpha \beta}^{d i s}$ is defined as (23).

$$
G_{d i s(s)}^{d q-P I}=\frac{i_{\alpha \beta}^{r e s}}{i_{\alpha \beta}^{d i s}}=-\frac{c_{2}^{\prime} s^{2}+c_{1}^{\prime} s+c_{0}^{\prime}}{a_{2}^{\prime} s^{2}+a_{1}^{\prime} s+a_{0}^{\prime}}
$$

Where, $c_{2}^{\prime}=L_{a}, c_{1}^{\prime}=R_{a}-L_{a} j \omega_{r e}, c_{0}^{\prime}=-R_{a} j \omega_{r e}$. (23) confirms that the suppression performances on the positivephase disturbance components is different from that on the negative-phase disturbance components because it includes a complex number $j$. Therefore, it is possible to perform the same comparison using a bode diagram by using (15) and (23) because these equations have the same input and output frames.

Figure 5 and Fig. 6 show the bode diagram for each disturbance suppression performance. In Fig. 5 and Fig. 6, subfigures (a) and (b) show the suppression performances on the positive-phase disturbance components. Subfigures (c) and (d) show the suppression performances on the negativephase disturbance components. Both current controller gains are designed by the pole placement method as multiple roots in the desired pole $\omega_{c}=6280 \mathrm{rad} / \mathrm{s}$. As shown in Fig. 5, the different disturbance suppression performances are obtained for the both disturbance components. In particular, Fig. 5 shows that the suppression performance on negative-phase disturbance components is inferior to that on the positivephase disturbance components. On the contrary, in the $\alpha-\beta$ sinusoidal current control as shown in Fig. 6, the disturbance suppression performance is the same for the positive-phase and negative-phase disturbance components. Therefore, in comparison with the bode diagrams of $d-q$ PI current control, it is confirmed that the proposed $\alpha-\beta$ sinusoidal current control has a high disturbance suppression performance.

\subsection{Structure of Disturbance Torque Hybrid Ob-} server This section considers a novel disturbance torque hybrid observer based on a DOB and a torque ripple table. The nominal torque ripple components $T_{R}$, which are saved in the torque ripple table, are used by the disturbance torque 


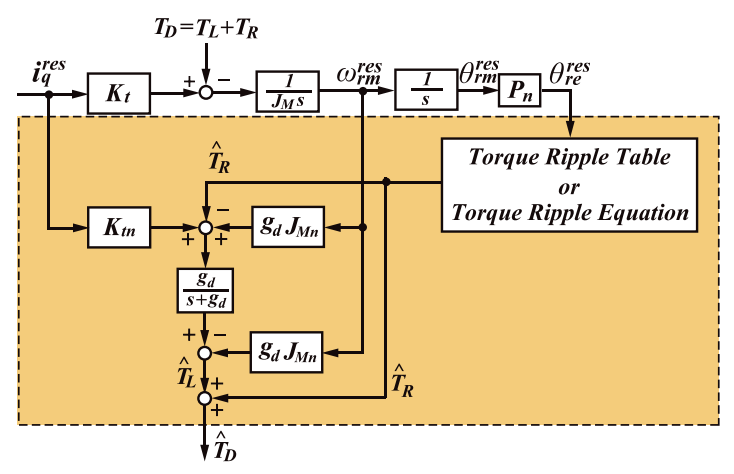

Fig. 7. Structure of disturbance torque hybrid observer

\section{hybrid observer.}

The estimated total disturbance torque $\hat{T}_{D}$ when using the DOB and the torque ripple table is expressed (24). In (24), the torque ripple is estimated twice using the DOB and the torque ripple table. Therefore, to avoid double compensation, it is necessary to add the output of the torque ripple table $\hat{T}_{R}$ to the DOB.

$$
\begin{aligned}
\hat{T}_{D} & =\frac{g_{d}}{s+g_{d}}\left(K_{t n} i_{q}-J_{M n} \omega_{r m} s\right)+\hat{T}_{R} \\
& =\frac{g_{d}}{s+g_{d}}\left(\hat{T}_{L}+\hat{T}_{R}\right)+\hat{T}_{R} \ldots \ldots
\end{aligned}
$$

The disturbance torque hybrid observer should utilize $\hat{T}_{R}$, which is estimated by the instantaneous disturbance torque. In the disturbance torque hybrid observer, the total disturbance torque $T_{D}$ is defined as shown in (25).

$$
\begin{aligned}
T_{D} & =\left(T_{l}+D_{M} \omega_{r m}+\Delta J_{M} \omega_{r m} s-\Delta K_{t} i_{q}\right)+T_{R} \\
& =T_{L}+T_{R} \ldots \ldots \ldots \ldots \ldots \ldots \ldots \ldots \ldots \ldots \ldots \ldots \ldots \ldots \ldots
\end{aligned}
$$

From (3) and the output $\hat{T}_{R}$ of the torque ripple table, the non-periodic disturbance torque $\hat{T}_{L}$ is defined as shown in (26). Here, a low-pass filter is utilized for noise reduction. In the disturbance torque hybrid observer, $\hat{T}_{D}$ is defined in (27) using $\hat{T}_{L}$ from (26) and $\hat{T}_{R}$. (27) can be transformed into (28).

$$
\begin{aligned}
\hat{T}_{L}= & \frac{g_{d}}{s+g_{d}}\left(K_{t n} i_{q}-J_{M n}\left(\omega_{r m}+\frac{\hat{T}_{R}}{J_{M n} s}\right) s\right) \ldots \ldots \\
\hat{T}_{D}= & \hat{T}_{L}+\hat{T}_{R} \\
= & \frac{g_{d}}{s+g_{d}}\left(K_{t n} i_{q}-J_{M n}\left(\begin{array}{c}
\left.\left.\omega_{r m}+\frac{\hat{T}_{R}}{J_{M n} s}\right) s\right)+\hat{T}_{R} \\
\ldots \ldots \ldots \ldots \ldots \ldots
\end{array}\right.\right. \\
\hat{T}_{D}= & \frac{g_{d}}{s+g_{d}}\left(K_{t n} i_{q}+g_{d} J_{M n} \omega_{r m}-\hat{T}_{R}\right) \\
& -g_{d} J_{M n} \omega_{r m}+\hat{T}_{R} \ldots \ldots \ldots \ldots \ldots \ldots
\end{aligned}
$$

Figure 7 shows the structure of the disturbance torque hybrid observer. As shown in Fig. 7, the inputs of the disturbance torque hybrid observer are the q-axis current response $i_{q}^{r e s}$, the mechanical angular speed response $\omega_{r m}^{r e s}$, and the electrical angular response $\theta_{r e}^{r e s}$. The study in (28) and Fig. 7 indicate that $\hat{T}_{R}$ is not affected by the low-pass filter. Therefore, the disturbance torque hybrid observer instantaneously compensates for the torque ripple components $T_{R}$, regardless of the bandwidth of the low-pass filter.

4.3 Saving Memory Method of Disturbance Torque Hybrid Observer In order to save the amount of DSP memory, this paper proposes a new application of the torque ripple equation which is reflected on the torque ripple table. When the proposed torque ripple equation is used instead of the torque ripple table, it is possible to save the amount of DSP memory.

A torque ripple equation is obtained by fitting this table, which uses an offline nonlinear least-squares method. When it is used that the linear approximation to a function $f$, which has the parameters $x_{k}(k=1,2,3, \ldots, n)$, in a Taylor Expansion, it is expressed as (30). Here, (29) is rewritten as (30).

$$
\begin{gathered}
\Delta f_{1}=f\left(x_{1}+\Delta x_{1}, \ldots, x_{n}+\Delta x_{n}\right)_{t=t_{1}}-f\left(x_{1}, \ldots, x_{n}\right)_{t=t_{1}} \\
\ldots \ldots \ldots \ldots \ldots \ldots \ldots(29) \\
\left.\Delta f_{1} \approx \frac{\partial f}{\partial x_{1}}\right|_{t=t_{1}} \Delta x_{1}+\cdots+\left.\frac{\partial f}{\partial x_{n}}\right|_{t=t_{1}} \Delta x_{n} \ldots \ldots \ldots .(30)
\end{gathered}
$$

If it has $m$ number of data, (30) is rewritten as (31).

$$
\left[\begin{array}{c}
\Delta f_{1} \\
\vdots \\
\Delta f_{m}
\end{array}\right]=J\left[\begin{array}{c}
\Delta x_{1} \\
\vdots \\
\Delta x_{n}
\end{array}\right]
$$

Where, $J$ is a Jacobian matrix that is defined as (32). In this offline nonlinear least-squares method, a pseudo-inverse matrix of the Jacobian matrix, expressed as (33), is used.

$$
\begin{aligned}
& J=\left[\begin{array}{ccc}
\left.\frac{\partial f}{\partial x_{1}}\right|_{t=t_{1}} & \cdots & \left.\frac{\partial f}{\partial x_{n}}\right|_{t=t_{1}} \\
\vdots & \ddots & \vdots \\
\left.\frac{\partial f}{\partial x_{1}}\right|_{t=t_{m}} & \cdots & \left.\frac{\partial f}{\partial x_{n}}\right|_{t=t_{m}}
\end{array}\right] \ldots \ldots \ldots \ldots \ldots \ldots \ldots \ldots \ldots \ldots \ldots \ldots \ldots \ldots
\end{aligned}
$$

Therefore, the error parameters $\Delta x_{k}$ from the optimal values are expressed as (34).

$$
\left[\begin{array}{c}
\Delta x_{1} \\
\vdots \\
\Delta x_{n}
\end{array}\right]=\left(J^{t} J\right)^{-1} J^{t}\left[\begin{array}{c}
\Delta f_{1} \\
\vdots \\
\Delta f_{m}
\end{array}\right]
$$

The parameters $x_{k}$ converge to the optimal values by performing an iterative calculation (34). The torque ripple table is fitted to the torque ripple equation by using this offline nonlinear least-squares method. The torque ripple equation is expressed as (35). (35) is used instead of the torque ripple table in Fig. 7.

$$
\hat{T}_{R}^{f i t}=\sum_{k=1}^{n} A_{k} \sin \left(k\left(\theta_{r e}-\theta_{k}\right)\right) \approx \hat{T}_{R} \ldots \ldots \ldots \ldots \ldots
$$

4.4 Structure of Proposed Position Servo System

Figure 8 shows a block diagram of the proposed position servo system. The disturbance torque hybrid observer is applied to the position servo system. The torque ripple table stores each component of the torque ripple, which causes degradation of the position control performance. The torque ripple table of the tested PMSM in this paper is measured 20 times offline. After averaging the data, 2048 data samples are obtained per period of the electrical angle $\theta_{\text {re }}$. The output waveform of torque ripple table is shown in Fig. 9(a). The output waveform of torque ripple equation is shown in Fig. 9(b), and the difference between the torque ripple table 


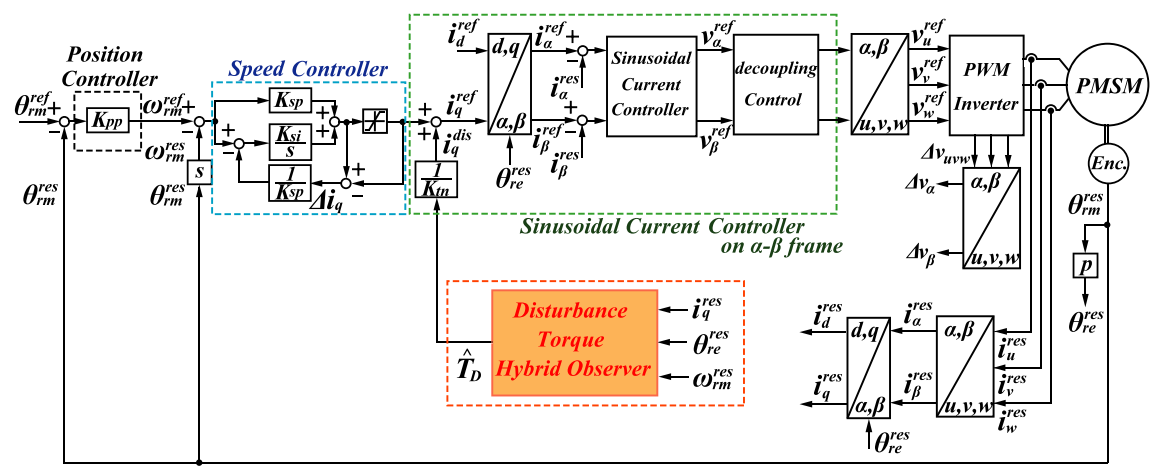

Fig. 8. Block diagram of proposed position servo system applying disturbance torque hybrid observer and $\alpha-\beta$ sinusoidal current control

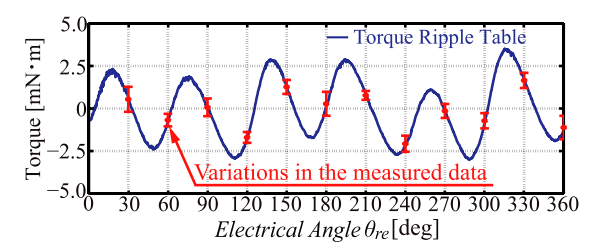

(a)

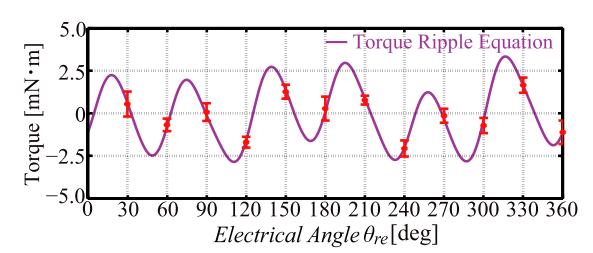

(b)

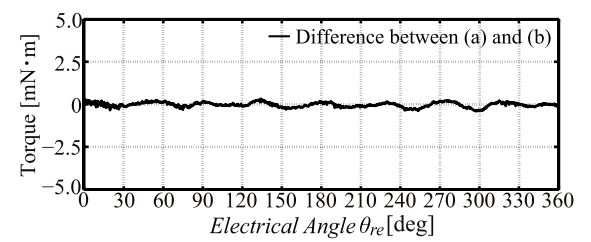

(c)

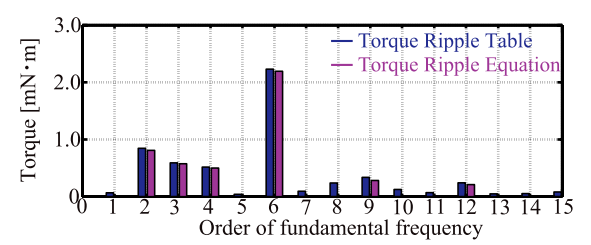

(d)

Fig. 9. Output waveforms of both torque ripple table and torque ripple equation. (a) Torque ripple table. (b) Torque ripple equation. (c) Difference between torque ripple table and torque ripple equation. (d) FFT analysis results of torque ripple table and torque ripple equation

and torque ripple equation is shown in Fig. 9(c). Figure 9(d) shows the FFT analysis results of torque ripple table and torque ripple equation. It is confirmed that the results of the torque ripple equation are almost same as the results listed in the torque ripple table. Table 1 summarizes the optimal values of each coefficient of the torque ripple equation. As the result, it is not necessary to provide a large DSP memory when the torque ripple equation is used by the disturbance torque hybrid observer.

\section{Numerical and Experimental Results}

5.1 Numerical Results

Table 2 summarizes the
Table 1. Optimal values of each coefficient of torque ripple equation

\begin{tabular}{c||c|c|c|c|c|c} 
Order $k$ & 6th & 2nd & 3rd & 4th & 9th & 12th \\
\hline \hline Amplitude $A_{k} \mathrm{mNm}$ & 2.318 & 0.757 & 0.480 & 0.243 & -0.247 & 0.205 \\
\hline Phase $\theta_{k}$ rad & 0.061 & 2.123 & 0.715 & 0.499 & -0.108 & 0.069
\end{tabular}

Table 2. Specifications of tested PMSM and control parameters

\begin{tabular}{cccc}
\hline \hline Parameter & Symbol & Specification & Unit \\
\hline \hline Rated Output & $P_{R}$ & 20 & $\mathrm{~W}$ \\
\hline Rated Speed & $N_{R}$ & 3000 & $\mathrm{~min}^{-1}$ \\
\hline Rated Torque & $T_{R}$ & 0.064 & $\mathrm{~N} \cdot \mathrm{m}$ \\
\hline Rated Current & $I_{R}$ & 2.3 & $\mathrm{Arms}$ \\
\hline Resistance & $R_{a}$ & 0.99 & $\Omega$ \\
\hline Inductance & $L_{a}$ & 0.24 & $\mathrm{mH}$ \\
\hline Torque Constant & $K_{t}$ & 0.0161 & $\mathrm{~N} \cdot \mathrm{m} / \mathrm{A}$ \\
\hline Linkage Flux & $\Phi_{a}$ & 0.0081 & $\mathrm{~Wb}$ \\
\hline Number of Pole Pairs & $P_{n}$ & 2 & - \\
\hline Rotor Inertia & $J_{M}$ & $0.31 \times 10^{-6}$ & $\mathrm{~kg} \cdot \mathrm{m}^{2}$ \\
\hline \hline Carrier Frequency & $f_{c}$ & 12.5 & $\mathrm{kHz}$ \\
\hline Current Control Bandwidth & $\omega_{c}$ & 6280 & $\mathrm{rad} / \mathrm{s}$ \\
\hline Speed Control Bandwidth & $\omega_{s}$ & 200 & $\mathrm{rad} / \mathrm{s}$ \\
\hline Cut-off Frequency of DOB & $g_{d}$ & 200 & $\mathrm{rad} / \mathrm{s}$ \\
\hline \hline
\end{tabular}

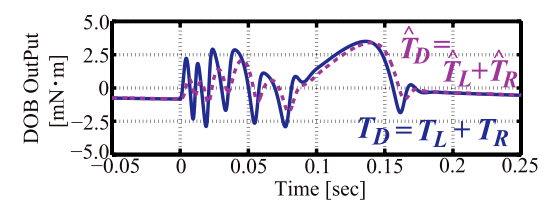

(a)

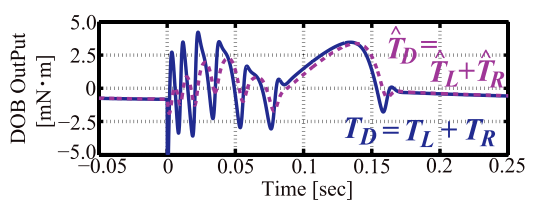

(b)

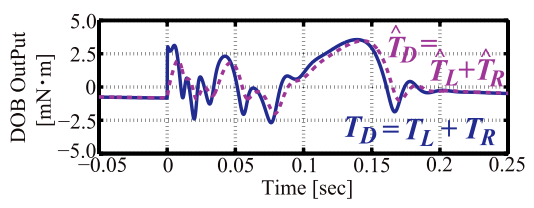

(c)

Fig. 10. Numerical simulation results of estimated disturbance torque by using DOB. (a) $J_{M}=J_{M n}\left(\alpha_{J}=1.0\right)$. (b) $J_{M}=0.5 J_{M n}\left(\alpha_{J}=0.5\right)$. (c) $J_{M}=2.0 J_{M n}\left(\alpha_{J}=2.0\right)$

specifications of tested PMSM and control parameters. The numerical results confirm that the disturbance torque hybrid observer effectively estimates the disturbance torque. In the 


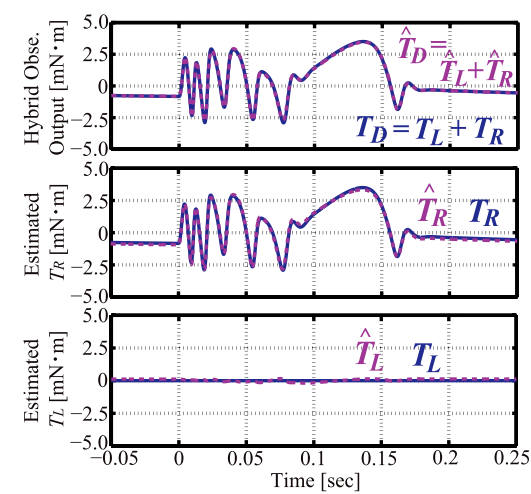

(a)
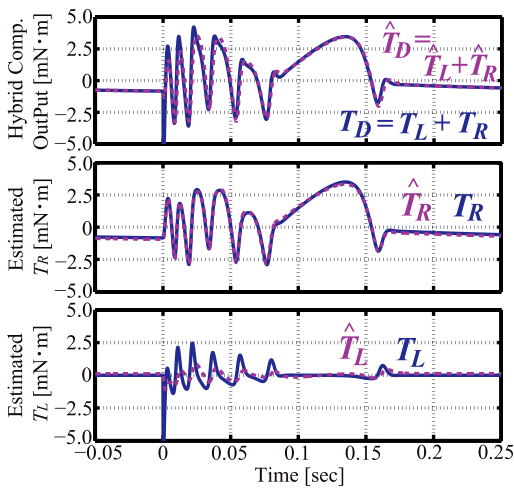

(b)

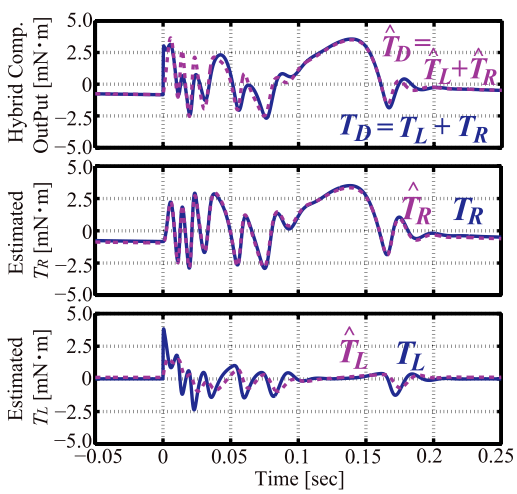

(c)

Fig. 11. Numerical simulation results of estimated disturbance torque by using disturbance torque hybrid observer (a) $J_{M}=J_{M n}\left(\alpha_{J}=1.0\right)$. (b) $J_{M}=0.5 J_{M n}\left(\alpha_{J}=\right.$ $0.5)$. (c) $J_{M}=2.0 J_{M n}\left(\alpha_{J}=2.0\right)$

numerical simulation, the proposed position servo system using an $\alpha-\beta$ sinusoidal current control is applied to the tested position control from $0^{\circ}$ to $180^{\circ}$ in $0 \mathrm{sec}$. Each observer estimates only the disturbance torque TD and does not connect to the current control system. Load-side torque $T_{l}$ and frictional coefficient $D_{M}$ are set as zero in this numerical simulation condition.

Figure 10 shows the numerical simulation results of the estimated disturbance torque by using DOB. In Fig. 10, the subfigure (a) shows the numerical simulation result under the condition of non-variation of inertia $\left(J_{M}=J_{M n}\right)$. The subfigures (b) and (c) show the numerical simulation results under the conditions of variation of inertia $\left(J_{M}=0.5 J_{M n}\right.$ and $J_{M}=$ $\left.2.0 J_{M n}\right)$. It is confirmed that a DOB causes phase and amplitude shifts in $\hat{T}_{D}$ under the all conditions. Therefore, it is

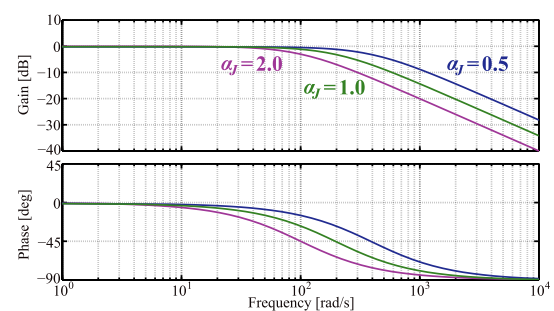

(a)

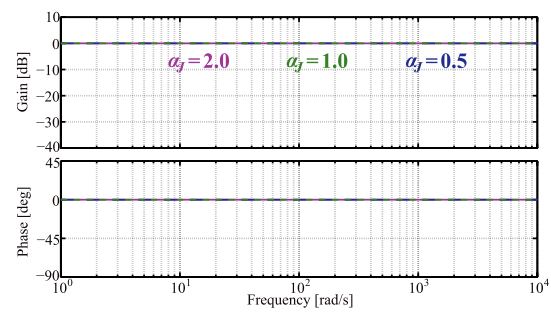

(b)

Fig. 12. Bode diagrams from torque ripple components $T_{R}$ to estimate value $\hat{T}_{R}$ under conditions of variation of inertia $J_{M}$. (a) DOB. (b) disturbance torque hybrid observer

very difficult to achieve an accurate and quick estimation of torque ripple. As the result, the position response causes a vibration.

Figure 11 shows the numerical simulation results of the estimated disturbance torque by using the disturbance torque hybrid observer with the torque ripple equation. In the case of non-variation of inertia, the disturbance torque hybrid observer accurately estimate $T_{D}$ as shown in Fig. 11(a). In the cases of variation of inertia, it is possible to accurately estimate torque ripple components $T_{R}$ by using the disturbance torque hybrid observer as shown in Fig. 11(b) and Fig. 11(c).

Next, the bode diagram from torque ripple components $T_{R}$ to estimate value $\hat{T}_{R}$ confirms the robustness to variation of inertia. (36) is the characteristic of disturbance estimation of DOB considering variation of inertia. (37) is that of the disturbance torque hybrid observer.

$$
\begin{aligned}
& \hat{T}_{D}=\frac{g_{d} \alpha_{J}^{-1}}{s+g_{d} \alpha_{J}^{-1}}\left(T_{L}+T_{R}\right) \ldots \ldots . \\
& \hat{T}_{D}=\frac{g_{d} \alpha_{J}^{-1}}{s+g_{d} \alpha_{J}^{-1}} T_{L}+\frac{s+g_{d} \alpha_{J}^{-1}}{s+g_{d} \alpha_{J}^{-1}} T_{R}
\end{aligned}
$$

Where, $\alpha_{J}=J_{M} / J_{M n}$. Figure 12 shows the bode diagrams from $T_{R}$ to $\hat{T}_{R}$ under conditions of variation of inertia $J_{M}$. In the DOB, $\hat{T}_{R}$ is affected by a low-pass filter as shown in Fig. 12(a). In addition, the cut-off frequency of LPF $g_{d}$ is influenced by the inertia variations. In the disturbance torque hybrid observer, $\hat{T}_{R}$ is insensitive to the inertia variations as shown in Fig. 12(b). As the result, the disturbance torque hybrid observer has high robustness to variation of inertia for the estimation of $T_{R}$.

5.2 Experimental Results Figure 13 and Fig. 14 show the experimental results of positioning control by using the $d-q$ PI current control and DOB. Figure 15 shows the experimental results of positioning control by using the $d-q$ PI current control and disturbance torque hybrid observer with the proposed torque ripple equation. In Fig. 13 and Fig. 15, the position control bandwidth $\omega_{p}$ is $20 \mathrm{rad} / \mathrm{s}$ which is the 

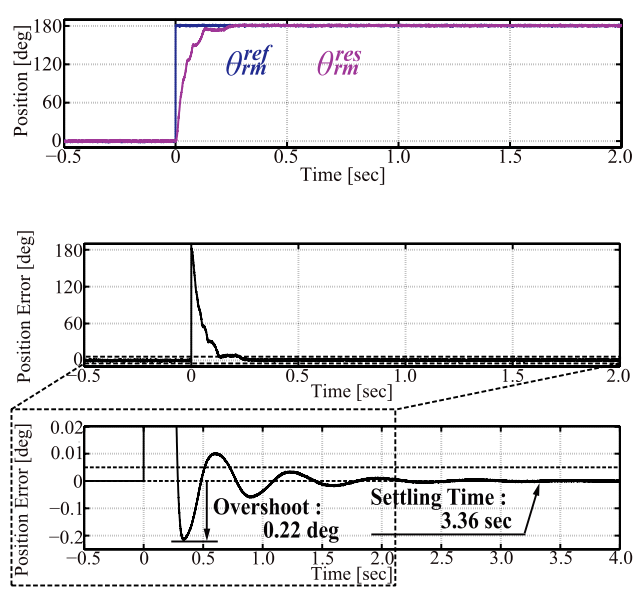

Fig. 13. Experimental results by using $d$ - $q$ PI current control and DOB $\left(\omega_{p}=20 \mathrm{rad} / \mathrm{s}\right)$. (a) Position response. (b) Position error
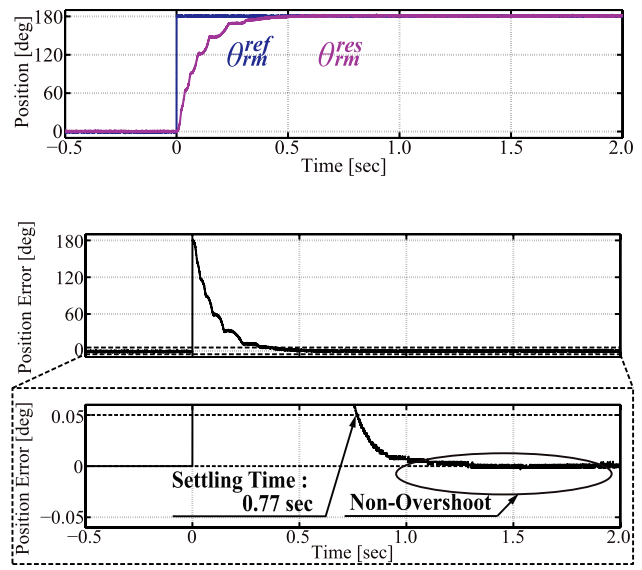

Fig. 14. Experimental results by using $d-q$ PI current control and DOB $\left(\omega_{p}=10 \mathrm{rad} / \mathrm{s}\right.$ : Design of nonovershoot). (a) Position response. (b) Position error
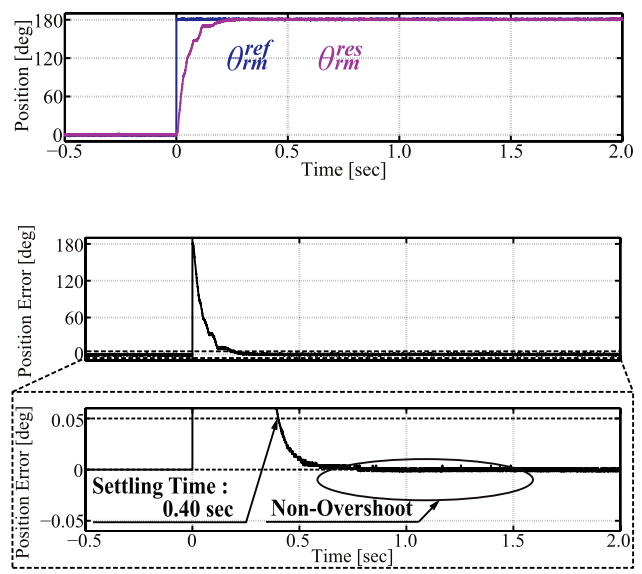

Fig. 15. Experimental results by using $d-q$ PI current control and disturbance torque hybrid observer with proposed torque ripple equation $\left(\omega_{p}=20 \mathrm{rad} / \mathrm{s}\right)$. (a) Position response. (b) Position error

standard design of positon controller. In Fig. 14, the position control bandwidth $\omega_{p}$ is $10 \mathrm{rad} / \mathrm{s}$ which is the design of non-overshoot of position response using DOB. The subfigures (a) show the position references and its responses. The subfigures (b) show the position errors between the position
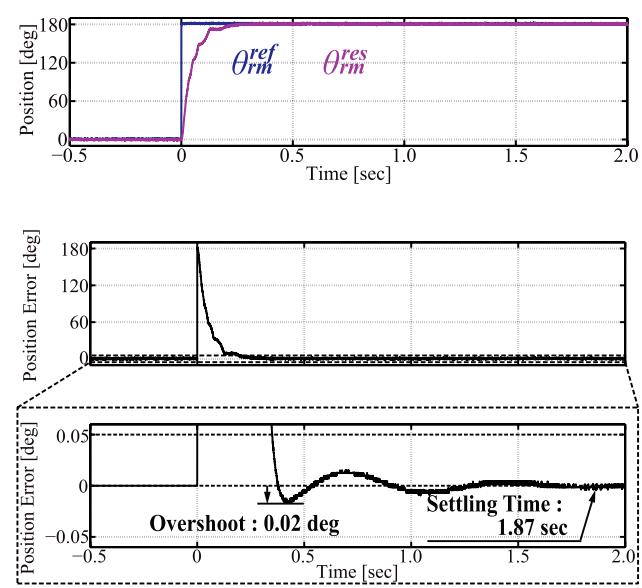

Fig. 16. Experimental results by using $\alpha-\beta$ sin current control and DOB $\left(\omega_{p}=20 \mathrm{rad} / \mathrm{s}\right)$. (a) Position response. (b) Position error
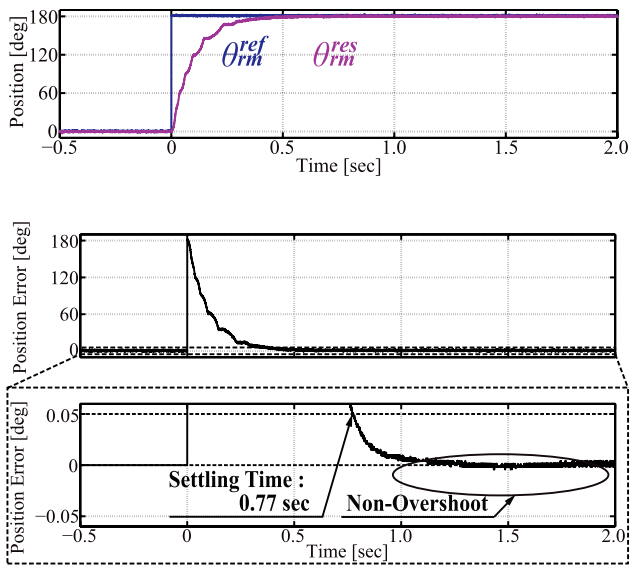

Fig. 17. Experimental results by using $\alpha-\beta$ sin PI current control and DOB $\left(\omega_{p}=10 \mathrm{rad} / \mathrm{s}\right.$ : Design of nonovershoot). (a) Position response. (b) Position error
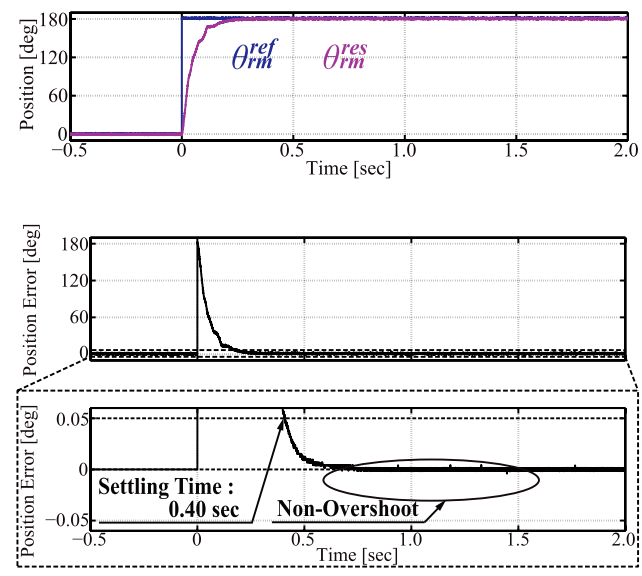

Fig. 18. Experimental results by using $\alpha-\beta$ sin current control and disturbance torque hybrid observer with proposed torque ripple equation ( $\left.\omega_{p}=20 \mathrm{rad} / \mathrm{s}\right)$. (a) Position response. (b) Position error

references and its responses. Figure 16, Fig. 17 and Fig. 18 show the experimental results of positioning control by using the $\alpha-\beta$ sin current control which is reflected on the $d-q$ PI current control.

Table 3 summarizes the settling time and overshoot of each 
Table 3. Experimental Results of settling time and overshoot of each position response

\begin{tabular}{|c|c|c|}
\hline Current Control System & \multicolumn{2}{|c|}{$d-q$ PI } \\
\hline Parameters & Settling time & Overshoot \\
\hline$\overline{\mathrm{DOB}}$ & & \\
\hline$\left(\omega_{p}=20 \mathrm{rad} / \mathrm{s}\right)$ & $3.36 \mathrm{sec}$ & $0.22 \mathrm{deg}$ \\
\hline$\overline{\mathrm{DOB}}$ & & \\
\hline$\left(\omega_{p}=10 \mathrm{rad} / \mathrm{s}:\right.$ Design of non-overshoot $)$ & $0.77 \mathrm{sec}$ & $0.00 \mathrm{deg}$ \\
\hline $\begin{array}{l}\text { Disturbance torque hybrid observer } \\
\qquad\left(\omega_{p}=20 \mathrm{rad} / \mathrm{s}\right)\end{array}$ & $0.40 \mathrm{sec}$ & $0.00 \mathrm{deg}$ \\
\hline Current Control System & \multicolumn{2}{|c|}{$\alpha-\beta$ sinusoidal } \\
\hline Parameters & Settling time & Overshoot \\
\hline $\begin{array}{c}\text { DOB } \\
\left(\omega_{p}=20 \mathrm{rad} / \mathrm{s}\right)\end{array}$ & $187 \mathrm{sec}$ & $002 \mathrm{dec}$ \\
\hline DOB & & \\
\hline$\left(\omega_{p}=10 \mathrm{rad} / \mathrm{s}:\right.$ Design of non-overshoot $)$ & $0.77 \mathrm{sec}$ & $0.00 \mathrm{deg}$ \\
\hline $\begin{array}{l}\text { Disturbance torque hybrid observer } \\
\qquad\left(\omega_{p}=20 \mathrm{rad} / \mathrm{s}\right)\end{array}$ & $0.40 \mathrm{sec}$ & $0.00 \mathrm{deg}$ \\
\hline
\end{tabular}

position response. In the case of using DOB and condition of $\omega_{p}=20 \mathrm{rad} / \mathrm{s}$, it is confirmed that the overshoot is reduced by using the proposed current control system on $\alpha-\beta$ stationary frame. Therefore, a high robust performance is obtained by using the proposed current control system on $\alpha-\beta$ stationary frame. Furthermore, it is confirmed that the settling time is reduced by using the disturbance torque hybrid observer under the condition of non-overshoot. As the results, the high performance positioning control is achieved by using the proposed position servo system which consists of the disturbance torque hybrid observer and proposed current control system on $\alpha-\beta$ stationary frame.

\section{Conclusion}

This paper proposes a new position servo system using a disturbance torque hybrid observer and a current control system in the $\alpha-\beta$ stationary frame, which has highly robust positioning control. This paper proposes the application of a torque ripple equation, which is reflected on the torque ripple table for the purpose of saving the amount of DSP memory.

The numerical simulation results confirm that the disturbance torque hybrid observer accurately estimates the instantaneous disturbance torque. Furthermore, the control performance of the disturbance torque hybrid observer with the proposed torque ripple equation is almost same as that of the disturbance torque hybrid observer using the torque ripple table.

The experimental results confirm the effectiveness of the proposed position servo system using the disturbance torque hybrid observer and the current control system in the $\alpha-\beta$ stationary frame. The current control system in the $\alpha-\beta$ stationary frame reduces the overshoot of the position response. Experimental results confirm that the settling time is reduced when using the disturbance torque hybrid observer under the condition of no overshoot. As a result, the proposed position servo system achieves high performance positioning control.

\section{References}

( 1 ) B. Ren, Q.-C. Zhong, and J. Chen: "Robust Control for a Class of Nonaffine Nonlinear Systems Based on the Uncertainty and Disturbance Estimator", IEEE Trans. on Industrial Electronics, Vol.62, No.9, pp.5881-5888 (2015)

( 2 ) S. Islam, P.X. Liu, G. Ombach, and A.E. Saddik: "Robust Control of FourRotor Unmanned Aerial Vehicle With Disturbance Uncertainty", IEEE Trans. on Industrial Electronics, Vol.62, No.3, pp.1563-1571 (2015)

( 3 ) Y. Zhou, H. Li, G. Meng, S. Zhou, and Q. Cao: "Analytical Calculation of Magnetic Field and Cogging Torque in Surface-Mounted Permanent-Magnet Machines Accounting for Any Eccentric Rotor Shape", IEEE Trans. on Industrial Electronics, Vol.62, No.6, pp.3438-3447 (2015)

( 4 ) K. Wang, Z.Q. Zhu, G. Ombach, and W. Chlebosz: "Average Torque Improvement of Interior Permanent-Magnet Machine Using Third Harmonic in Rotor Shape", IEEE Trans. on Industrial Electronics, Vol.61, No.9, pp.50475057 (2014)

( 5 ) J. Wanjiku, M.A. Khan, P.S. Barendse, and P. Pillay: "Influence of Slot Openings and Tooth Profile on Cogging Torque in Axial-Flux PM Machines", IEEE Trans. on Industrial Electronics, Vol.62, No.12, pp.7578-7589 (2015)

( 6 ) M. Kim, S.K. Sul, and J. Lee: "Compensation of Current Measurement Error for Current-Controlled PMSM Drives", IEEE Trans. on Industry Applications, Vol.50, No.5, pp.3365-3373 (2014)

( 7 ) A. Lewicki: "Dead-Time Effect Compensation Based on Additional Phase Current Measurements", IEEE Trans. on Industrial Electronics, Vol.62, No.7, pp.4078-4085 (2015)

( 8 ) S.Y. Kim, W. Lee, M.S. Rho, and S.Y. Park: "Effective Dead-Time Compensation Using a Simple Vectorial Disturbance Estimator in PMSM Drives", IEEE Trans. on Industrial Electronics, Vol.57, No.5, pp.1609-1614 (2010)

( 9 ) S. Katsura, K. Irie, and K. Ohishi: "Wideband Force Control by PositionAcceleration Integrated Disturbance Observer", IEEE Trans. on Industrial Electronics, Vol.55, No.4, pp.1699-1706 (2008)

(10) M. Chen and S.S. Ge: "Adaptive Neural Output Feedback Control of Uncertain Nonlinear Systems With Unknown Hysteresis Using Disturbance Observer", IEEE Trans. on Industrial Electronics, Vol.62, No.12, pp.7706-7716 (2015)

(11) Z. Ding: "Consensus Disturbance Rejection With Disturbance Observers", IEEE Trans. on Industrial Electronics, Vol.62, No.9, pp.5829-5837 (2015)

(12) D. Ginoya, P.D. Shendge, and S.B. Phadke: "Delta-Operator-Based Extended Disturbance Observer and Its Applications", IEEE Trans. on Industrial Electronics, Vol.62, No.9, pp.5817-5828 (2015)

(13) E. Sariyildiz and K. Ohnishi: "On the Explicit Robust Force Control via Disturbance Observer", IEEE Trans. on Industrial Electronics, Vol.62, No.3, pp.1581-1589 (2015)

(14) E. Sariyildiz and K. Ohnishi: "Stability and Robustness of DisturbanceObserver-Based Motion Control Systems", IEEE Trans. on Industrial Electronics, Vol.62, No.1, pp.414-422 (2015)

(15) S. Komada, N. Machii, and T. Hori: "Control of Redundant Manipulators Considering Order of Disturbance Observer", IEEE Trans. on Industrial Electronics, Vol.47, No.2, pp.413-420 (2000)

(16) H. Kobayashi, S. Katsura, and K. Ohnishi: "An Analysis of Parameter Variations of Disturbance Observer for Motion Control”, IEEE Trans. on Industrial Electronics, Vol.54, No.6, pp.3413-3421 (2007)

(17) W. Qian, S.K. Panda, and J.X. Xu: "Torque Ripple Minimization in PM Synchronous Motors Using Iterative Learning Control", IEEE Trans. on Power Electronics, Vol.19, No.2, pp.272-279 (2004)

(18) P. Mattaveli, L. Tubiana, and M. Zigliotto: "Torque-Ripple Reduction in PM Synchronous Motor Drives Using Repetitive Current Control", IEEE Trans. on Power Electronics, Vol.20, No.6, pp.1423-1431 (2008)

(19) S. Chen and T. Sekiguchi: "High Efficiency and Low Torque Ripple Control of Permanent Magnet Synchronous Motor Based on the Current Tracking Vector of Electromotive Force", IEEJ Trans. of IA, Vol.120, No.4, pp.559565 (2000)

(20) S. Sinnaka and H. Kishida: "New Simple Torque-Sensorless Torque Control for Quasi-Perfect Compensation of 6th Harmonic Torque Ripple Due to Nonsinusoidal Distribution of Back EMF of PMSM", IEEJ Trans. of IA, Vol.131, No.8, pp.1068-1077 (2011)

(21) Y. Tadano, T. Akiyama, M. Nomura, and M. Ishida: "Torque Ripple Suppression Control Based on the Periodic Disturbance Observer with a Complex Vector Representation for Permanent Magnet Synchronous Motors", IEEJ Trans. of IA, Vol.132, No.1, pp.84-93 (2012)

(22) Y.A.-R.I. Mohamed: "Design and Implementation of a Robust CurrentControl Scheme for a PMSM Vector Drive With a Simple Adaptive Disturbance Observer", IEEE Trans. on Industrial Electronics, Vol.54, No.4, pp.1981-1988 (2007)

(23) Y.A.-R.I. Mohamed: "A Newly Designed Instantaneous-Torque Control of Direct-Drive PMSM Servo Actuator With Improved Torque Estimation and Control Characteristics", IEEE Trans. on Industrial Electronics, Vol.54, No.5, pp.2864-2873 (2007)

(24) C.K. Lai and K.K. Shyu: "A novel motor drive design for incremental motion system via sliding-mode control method", IEEE Trans. on Industrial Electronics, Vol.52, No.2, pp.499-507 (2005)

(25) Y. Peng, D. Varncic, and R. Honus: "Anti-windup, bumpless, and conditioned transfer techniques for PID controllers", IEEE Control Syst. Mag., Vol.16, 
No.4, pp.48-57 (1996)

(26) H.-B. Shin and J.-G. Park: "Anti-windup PID controller with integral state predictor for variable-speed motor drives", IEEE Trans. on Industrial Electronics, Vol.59, No.3, pp.1509-1516 (2012)

(27) S. Tarbouriech and M. Turner: "Anti-windup design: An overview of some recent advances and open problems", IET Control Theory Appl., Vol.3, pp.119 (2009)

(28) K. Ohishi, E. Hayasaka, T. Nagano, M. Harakawa, and T. Kanmachi: "High-Performance Speed Servo System Considering Voltage Saturation of a Vector-Contorlled Induction Motor", IEEE Trans. on Industrial Electronics, Vol.53, No.3, pp.795-802 (2006)

(29) K. Takahashi, K. Ohishi, and T. Kanmachi: "High-performance Inverter Based on Shaft Acceleration Torque for AC Drives", IEEE Trans. on Industrial Electronics, Vol.60, No.1, pp.66-77 (2013)

(30) J. Kitajima, K. Ohishi, and Y. Seki: "Rapid and Stable Speed Response Based on Current Differential Signal and Priority Amplitude Method of SVM in Flux-Weakening Region of SPMSM", IEEJ Journal of IA, Vol.4, No.3, pp.107-115 (2015)

(31) H. Nakano, M. Naitoh, R. Kondo, H. Eda, J. Shimizu, and Y. Yamamoto: "Novel Analysis Method Based on Extended Bode Diagram for High-pass Filter Using Rotating Coodinate Transformations", T. IEE Japan D, Vol.119D, No.2, pp.175-181 (1999)

(32) H. Nakano, M. Jibiki, A. Nabae, and Y. Okamura: "Variable Frequency Inverter with Sinusoidal Voltage Outputs Using Rotating Coordinate Transformation", T. IEE Japan D, Vol.115-D, No.6, pp.735-742 (1995)

Yoshiaki Seki (Student Member) received B.E. degrees in electrical

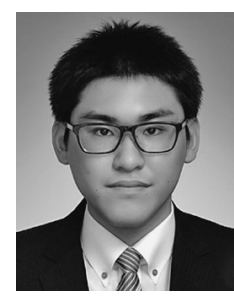
engineering from Nagaoka University of Technology, Nagaoka, Japan, in 2014. Now he is a candidate of the M.E. degree in Electrical, Electronics and Information Engineering. His research interests include motion control and motor drive. He is a member of the Institute of Electrical Engineering of Japan.

Kiyoshi Ohishi (Fellow) received the B.E., M.E., and Ph.D. de-

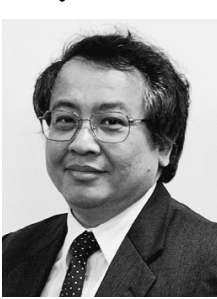
grees in electrical engineering from Keio University, Yokohama, Japan, in 1981, 1983, and 1986, respectively. From 1986 to 1993, Prof. Ohishi was an Associate Professor with Osaka Institute of Technology, Osaka, Japan. Since 1993, he has been with Nagaoka University of Technology, Nagaoka, Japan. He became a Professor in 2003. His research interests include motion control, mechatronics, robotics and power electronics. He is a General chair of IEEE IECON2015, AMC2010 and AMC2016. He also contributes as an AdCom Member of IEEE/IES and an Associate Editor for the IEEE Transactions on Industrial Electronics. He is a member of the Institute of Electrical Engineering of Japan and the Robotics Society of Japan. He received the Outstanding Paper Awards at IECON'85 and Best Paper Awards at IECON'02, IECON'04 from the IEEE Industrial Electronics Society.

Yuki Yokokura (Member) received the B.E. and M.E. degrees in elec-

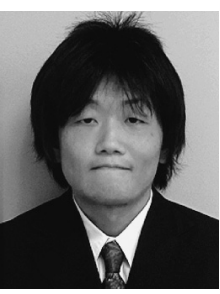
trical engineering from Nagaoka University of Technology, Niigata, Japan, in 2007 and 2009, respectively. In 2011, he received Ph.D. degree in integrated design engineering from Keio University, Yokohama, Japan. From 2010 to 2011, he was a JSPS (Japan Society for the Promotion of Science) Research Fellow (DC2 and PD). He was a Visiting Fellow at Keio University, and a Postdoctoral Fellow at Nagaoka University of Technology in 2011. Since 2012, he has been an Assistant Professor with Nagaoka University of Technology. His research interests include motion control, motor drive, powerelectronics, and real-world haptics.
Toshiki Sano (Student Member) is a candidate of the B.E. degree in

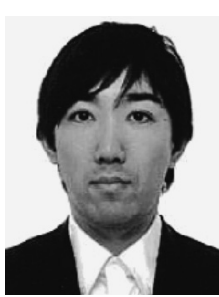
Electrical, Electronics and Information Engineering. His research interests include motion control and motor drive. He is a member of the Institute of Electrical Engineering of Japan.

Yuji Ide (Member) received M.E. degrees in Electrical Engineering

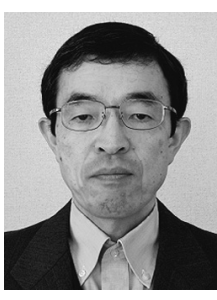
from Nagaoka University of Technology, Nagaoka, Japan, in 1990. He is currently with Sanyo Denki Co., Ltd., Ueda, Japan. His research interests include motor drive and power electronics. He is a member of the Institute of Electrical Engineering of Japan.

Daigo Kuraishi (Member) received the B.S. and M.S. degree in elec-

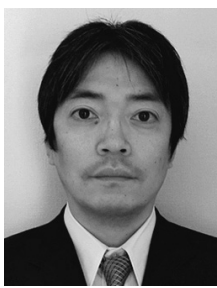
trical engineering from Nagaoka University of Technology, Nagaoka, Japan, in 1997 and 1999, respectively. He is currently with Sanyo Denki Co., Ltd., Ueda, Japan. His research interests include design of servo motors. He is a member of the Institute of Electrical Engineering of Japan.

Akihiko Takahashi (Non-member) received the B.S. and M.S. degree

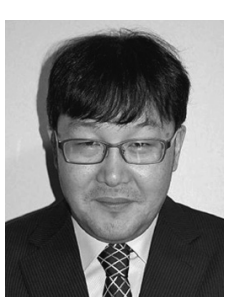
in electrical engineering from Nagaoka University of Technology, Nagaoka, Japan, in 1993 and 1995, respectively. He is currently with Sanyo Denki Co., Ltd., Ueda, Japan. His research interests include design of servo motors. 